\title{
COMPREHENSIVE EFFECT OF OPERATIONAL FACTORS ON TRANSPORT EFFICIENCY OF A HIGH-SPEED RAILWAY TRAIN
}

\author{
Xuesong Feng, Yuanpeng Jie, Haidong Liu, Bin Xu
}

Original scientific paper Based on computer-aided simulation studies, the comprehensive effect of target speed, Passenger Capacity Utilization Rate (PCUR) and formation of a High-Speed Railway (HSR) train on its transport efficiency is analysed in this research. It is found that if the target speed of a HSR train is no lower than approximately $80 \%$ of its designed top speed, the time expense per unit of the passenger-kilometres completed by this train will be relatively very small when the PCUR of the train becomes more than about $60 \%$. From the perspectives of both efficiency and sustainability, it is suggested that the PCUR of a HSR ought to be over $60 \%$ and, meanwhile, its target speed should be about $80 \%$ of its designed top speed. In addition, the long formation of a HSR train is preferred if its PCUR can be kept over $60 \%$.

Keywords: high-speed railway train; Passenger Capacity Utilization Rate (PCUR); simulation analysis; target speed; train formation; transport efficiency

\section{Sveobuhvatni učinak radnih čimbenika na prijevoznu učinkovitost vlaka velike brzine}

Izvomi znanstveni članak Na temelju računalnih simulacijskih analiza, u ovom se istraživanju analizira učinak zadane brzine, stope iskoristivosti kapaciteta putnika (Passenger Capacity Utilization Rate - PCUR) i formacije željezničkog vlaka velike brzine (High-Speed Railway - HSR) na njegovu prijevoznu učinkovitost. Ustanovljeno je da ako zadana brzina HSR vlaka nije manja od oko 80 \% vršne projektne brzine, utrošak vremena tog vlaka po jedinici putnik-kilometri bit će relativno vrlo malen kad PCUR vlaka postane veći od oko $60 \%$. I sa stajališta učinkovitosti i održivosti, predlaže se da bi PCUR vlaka velike brzine - HSR trebao biti preko $60 \%$, a zadana brzina oko $80 \%$ maksimalne projektne brzine. Osim toga, preferira se duga formacija HSR vlaka ako se njegov PCUR može zadržati iznad $60 \%$.

Ključne riječi: formacija vlaka; prijevozna učinkovitost; simulacijska analiza; stopa iskoristivosti kapaciteta putnika; zadana brzina; željeznički vlak velike brzine

\section{Introduction}

A High-Speed Railway (HSR) line is defined in China as a passenger dedicated railway line where trains whose designed top speeds are no lower than 250 kilometres per hour $(\mathrm{km} / \mathrm{h})$ run with their target speeds over $200 \mathrm{~km} / \mathrm{h}$ in the initial operation stage of the HSR line [1]. Since the first Chinese HSR line connecting Beijing and Tianjin was put into operation in 2008, China today has established the most extensive HSR network in the world [2]. With the improvement of the HSR network, the intercity passenger transports in China are more and more dependent on the HSR trains, as proved in Tab. 1 which is made according to [3], mainly owing to the passenger travel time saving effect of their fast transport services. As a result, rationalising the utilizations of the HSR trains on the basis of various transport conditions to improve their passenger transport efficiencies from the perspective of railway passenger transport management has become an important task of the researchers as well as the practitioners in China now.

Table 1 Passenger trips and their shares

\begin{tabular}{|c|c|c|}
\hline Year & $\begin{array}{c}\text { HSR Passenger Trips } \\
\text { (Million) }\end{array}$ & $\begin{array}{c}\text { Shares of HSR Passenger } \\
\text { Trips in All Railway } \\
\text { Passenger Trips (\%) }\end{array}$ \\
\hline 2008 & 7,34 & 0,50 \\
\hline 2009 & 36,51 & 3,10 \\
\hline 2010 & 133,23 & 8,50 \\
\hline 2011 & 285,52 & 15,80 \\
\hline 2012 & 388,15 & 20,50 \\
\hline
\end{tabular}

Great efforts have been continuously made to improve the rail passenger transport efficiency. A considerable number of the studies concentrate on reducing the passenger waiting time of trains through the scheduling optimisation of their transport services. As to a rail line in a dynamic passenger demand environment, mathematical programming formulations yielding train timetables which may not be regular or periodic are proposed by Barrena et al. [4, 5] for the minimisations of the average waiting time of the passengers at the stations. The yielded train timetables are adapted to different distributions of the travel demands between the stations in various time periods. In a similar way, Niu et al. [6] develop nonlinear mixed integer programming models to produce non-periodic train diagrams with the skip-stop patterns of the trains predetermined, in order to minimise the total waiting time of the passengers at each of the stations along a rail corridor. In view of the insufficient ability of a one-dimensional objective to select the best transport schedule for saving the passenger waiting time, Isaai et al. [7] suggest an approach within the framework of the fuzzy Analytic Hierarchy Process. Sum of weighted waiting time, average of unit waiting time and maximum ratio of waiting time to journey time are accordingly evaluated for a train timetable to judge its goodness via the aggregation of these indices.

Apart from shortening the passenger waiting time as much as possible by optimising train schedules, reducing the riding time of passengers, decreasing the time consumed in transfers, etc. are also key research topics for the improvement of rail transport efficiency. It has to be noted that at the expense of the obvious energy cost increase of a train with its target speed [8,9], an excessively improved target speed will not contribute much more to saving the train travel time especially when 
the transport distance between neighbouring stops of the train is relatively short $[9,10]$. Rather than irrationally increasing the target speed of a train, improving the average speed of the train in its entire transport process is the key to the effective reduction of its passenger riding time [11]. As a result, according to actual situations, different target speeds should be set for trains. Focusing on a HSR line in an existing network, Zhou and Zhong [12] design a branch-and-bound algorithm with effective dominance rules to generate Pareto solutions to minimising the total travel time of high-speed and medium-speed trains as well as the expected waiting time for trains. In consideration of both the transfer walking distances and the transfer passenger flows, Feng et al. [13] establish an optimisation model to minimise the average waiting time of the passengers making different transfers inside a rail station with rationalising the arrival and departure time of the trains. Taking into account not only decreasing the riding time of passengers and their transfers in a trip but also increasing the transport service frequency of the trains on each rail route and their average Passenger Capacity Utilization Rate (PCUR), an integrated hierarchical approach with different grades of the target speeds of trains predetermined is put forward by $\mathrm{Fu}$ et al. [14] to devise a set of train diagrams for a HSR network. According to passenger preferences, EspinosaAranda et al. [15] propose an optimisation model solved by hybridizing a Standard Particle Swarm Optimisation and Nealder-Mead methods to improve the train schedule of a HSR line. This model consists of a discrete event simulation model representing the supply of train services and a constrained choice model evaluating the attributes (e.g. waiting and riding time, seat availabilities and fares) of train services.

Because of the unremitting efforts, many valuable research findings have been obtained for the improvement of rail passenger transport efficiency. However, the exact integrated effect of various factors including target speed, PCUR and so on of a HSR train on the time cost per unit of its completed transport workload has not been fully clarified. Therefore, the changes of the Transport Time (TT) (i.e., the entire travel time minus the stop time in all the intermediate stations) per 10000 passenger-kilometres (p-km) completed by a HSR train with its target speed, PCUR and formation are quantitatively analysed in detail in this research. All the quantificational analyses in this work are based on simulating the transport operations of two representative types of the HSR trains on certain rail routes in China.

The contents of this paper are organized as follows. The studied HSR trains and rail routes are introduced in Section 2. Next, the simulation approach proposed to analyse the TT of a transport work completed by a HSR train is explained in Section 3. Thereafter, Section 4 compares TT per $10000 \mathrm{p}-\mathrm{km}$ of the simulated transports made by a HSR train with different target speeds and PCURs on the same rail route for a certain formation of the train. Then, the influence of some formations and PCURs of a HSR train upon the TT per $10000 \mathrm{p}-\mathrm{km}$ of the same transport service provided by this train is analysed for various target speeds in Section 5. Finally, Section 6 draws conclusions and proposes some future research issues.

\section{Studied trains and rail routes}

The two types of the HSR trains studied in this research are named HSR-1 and HSR-2 whose designed top speeds are $350 \mathrm{~km} / \mathrm{h}$ and $250 \mathrm{~km} / \mathrm{h}$, respectively. As illustrated in Fig. 1, both of these two types of the trains operating on their corresponding rail routes take the formation consisting of 8 cars at present. The length of such a HSR-1 is 200,7 metres $(\mathrm{m})$. It weighs 380 tons $(\mathrm{t})$. In contrast, a HSR-2 taking the same formation is $10,8 \mathrm{~m}$ longer and has an additional mass of $71 \mathrm{t}$. Moreover, the passenger capacity of a HSR-1 formed as shown in Fig. 1 is 600 and a corresponding HSR-2 has 622 passenger seats. Because the average mass of a railway passenger together with his/her hand baggage is 80 kilograms $(\mathrm{kg})$ [16], the total mass of the passengers together with their hand baggage in a HSR-1 composed as explained in Fig. 1 is $48 \mathrm{t}$ when all the passenger seats of the train are used. By comparison, if the passenger capacity of a HSR-2 taking the same formation is fully utilized, all its passengers and their hand baggage weighs 49,76 t. The studied HSR-1 and HSR-2 provide passenger transport services on the corresponding rail routes (i.e., L1 and L2) whose lengths are $116,91 \mathrm{~km}$ and $170,53 \mathrm{~km}$, respectively. The transport distances between all the neighbouring stations on L1 and L2 are presented in Tab. 2 .

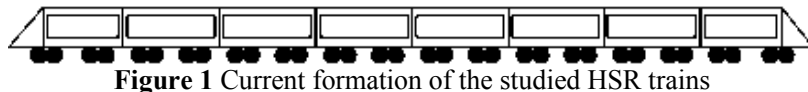

Table 2 Transport distances between neighbouring stations

\begin{tabular}{|c|c|c|}
\hline $\begin{array}{c}\text { Rail } \\
\text { Route }\end{array}$ & Inter-station Section & $\begin{array}{c}\text { Transport Distance } \\
(\mathrm{km})\end{array}$ \\
\hline \multirow{4}{*}{ L1 } & $\begin{array}{c}\text { From Station L1-1 to } \\
\text { Station L1-2 }\end{array}$ & 83,25 \\
\cline { 2 - 3 } & $\begin{array}{c}\text { From Station L1-2 to } \\
\text { Station L1-3 }\end{array}$ & 33,66 \\
\hline \multirow{4}{*}{ L2 } & $\begin{array}{c}\text { From Station L2-1 to } \\
\text { Station L2-2 }\end{array}$ & 41,80 \\
\cline { 2 - 3 } & $\begin{array}{c}\text { From Station L2-2 to } \\
\text { Station L2-3 }\end{array}$ & 55,09 \\
\cline { 2 - 3 } & $\begin{array}{c}\text { From Station L2-3 to } \\
\text { Station L2-4 }\end{array}$ & 73,64 \\
\hline
\end{tabular}

\section{Simulation approach}

In the simulation modelling work of this study, a train is considered as a thread with its mass equally distributed. Furthermore, it is assumed that the total mass of the passengers together with their hand baggage also has equal allocations on this thread. The operations of a train in all the equivalent computation intervals (i.e., 0,01 second here) are successively simulated for the whole process of the passenger transport from the departure station of the train to its terminal station. The traction force of a train in a computation interval is explained by Eq. (1). If a train motors for its start-up, its traction force is unchanged. If the train brakes or coasts after its startup, it stops motoring and, as a result, has no traction powers. 


$$
F(k)=\left\{\begin{array}{l}
F, \text { if }(v(k-1)=0 \text { and } P(k)>0) \\
P(k) / v(k-1), \text { if }(v(k-1)>0)
\end{array}\right.
$$

where,

$F(k)$ - Traction force in the $k^{\text {th }}$ computation interval ( $k$ $=1,2, \ldots), \mathrm{N}$

$F-$ Traction force when the train starts up, N

$v(k-1)-$ Speed at the end of the $(k-1)^{\text {th }}$ computation interval, $\mathrm{m} / \mathrm{s}$

$P(k)$ - Traction power in the $k^{\text {th }}$ computation interval after its startup, W.

It is revealed by Eq. (2) that the resistance to the movement of a train consists of both the basic resistance and the additional resistance. Mainly because of the friction between the rail and the wheels of a train, the basic resistance is proportional to the mass of the train when it starts up, as interpreted in Eq. (3). The value of the resistance intensity at this time is negative. The basic resistance after the start-up of a train is decided by not only the speed of the train because of the air drag but also its streamline structure which works on the aerodynamic characteristics of the train through the negative resistance coefficients. In contrast, the sources of the additional resistance to the movement of a train include rail slope, rail curve, wind, etc. The rail slope resistance is, for instance, explained by Eq. (4).

$$
f(k)=f_{k}^{b}+f_{k}^{a}
$$

where,

$f(k)$ - Resistance in the $k^{\text {th }}$ computation interval, N

$f_{k}^{b}$ - Basic resistance in the $k^{\text {th }}$ computation interval, $\mathrm{N}$

$f_{k}^{a}$ - Additional resistance in the $k^{\text {th }}$ computation interval, $\mathrm{N}$.

$$
f_{k}^{b}=\left\{\begin{array}{l}
q \times M, \text { if }(v(k-1)=0 \text { and } P(k)>0) \\
\alpha_{0}+\alpha_{1} \times(v(k-1))+\alpha_{2} \times(v(k-1))^{2}, \text { if }(v(k-1)>0)
\end{array}\right.
$$

where,

$q$ - Resistance intensity for startup of a train, $\mathrm{N} / \mathrm{kg}$

$M$ - Mass of the train, $\mathrm{kg}$

$\alpha_{0}, \alpha_{1}, \alpha_{2}-$ Resistance coefficients for the movement of the train after its start-up.

$f_{k}^{R}=-m_{k}^{R} \times g \times \sin \alpha$

where,

$f_{k}^{R}-$ Resistance because of the ramp $R$ in the $k^{\text {th }}$ computation interval, $\mathrm{N}$

$m_{k}^{R}$ - Total mass of the cars on the ramp $R$ in the $k^{\text {th }}$ computation interval, $\mathrm{kg}$

$g-$ Gravitational acceleration, $\mathrm{N} / \mathrm{kg}$

$\alpha$ - Acute angle between the horizontal line and the slope of the ramp $R, \circ$.
According to the operation (i.e., motoring, coasting or braking) of a train in a computation interval, the acceleration of the train in such a time is generally interpreted by Eq. (5). The braking force of a train is constant when braking is applied. The speed of a train at the end of a computation interval and its transport distance in this interval are determined by Eq. (6) and Eq. (7), respectively.

$a(k)=\left\{\begin{array}{l}(F(k)+f(k)) / M, \text { (Motoring) } \\ f(k) / M,(\text { Coasting) } \\ (f(k)+f(B)) / M, \text { (Braking) }\end{array}\right.$

where,

$a(k)$ - Acceleration of a train in the $k^{\text {th }}$ computation interval, $\mathrm{N} / \mathrm{kg}$

$f(B)$ - Braking force of the train when it is braking, $\mathrm{N}$.

$v(k)=v(k-1)+a(k) \times \Delta$

where,

$v(k)$ - Speed at the end of the $k^{\text {th }}$ computation interval, $\mathrm{m} / \mathrm{s}$

$\Delta-$ Computation interval.

$d(k)=v(k-1) \times \Delta+\frac{1}{2} \times a(k) \times \Delta^{2}$

where $d(k)$ stands for transport distance in the $k^{\text {th }}$ computation interval, $\mathrm{m}$.

In order to fully reflect the impacts of the target speed, PCUR and formation of a train on its TT, the train starts up as soon as it stops at an intermediate station. At the end of each computation interval, the speed of the train is compared with the top speed required at the nearest speed limit rail site ahead the train. The train brakes if the difference between its conservative breaking acceleration and the necessary negative acceleration to meet the nearest speed limit requirement becomes smaller than a certain value. The conservative breaking acceleration of a train and the necessary negative acceleration to satisfy the nearest speed limit ahead the train are explained by Eq. (8) and Eq. (9), respectively.

$a(B)=\beta \times f(B) / M$

where,

$a(B)$ - Conservative breaking acceleration, $\mathrm{N} / \mathrm{kg}$ $\beta$ - Conservative coefficient (i.e., $0<\beta<1$ ).

$a(l)=\frac{(v(k-1))^{2}-(v(l))^{2}}{2 \times(D(l)-d)}$

where,

$a(l)$ - Necessary negative acceleration to satisfy the nearest speed limit required at the rail site $l, \mathrm{~N} / \mathrm{kg}$

$v(l)$ - Speed limit at the rail site $l, \mathrm{~m} / \mathrm{s}$

$D(l)$ - Transport distance from the departure station to the rail site $l, \mathrm{~m}$

$d$-Completed transport distance, $\mathrm{m}$. 
The flowchart of the simulation approach in this research is shown in Fig. 2.

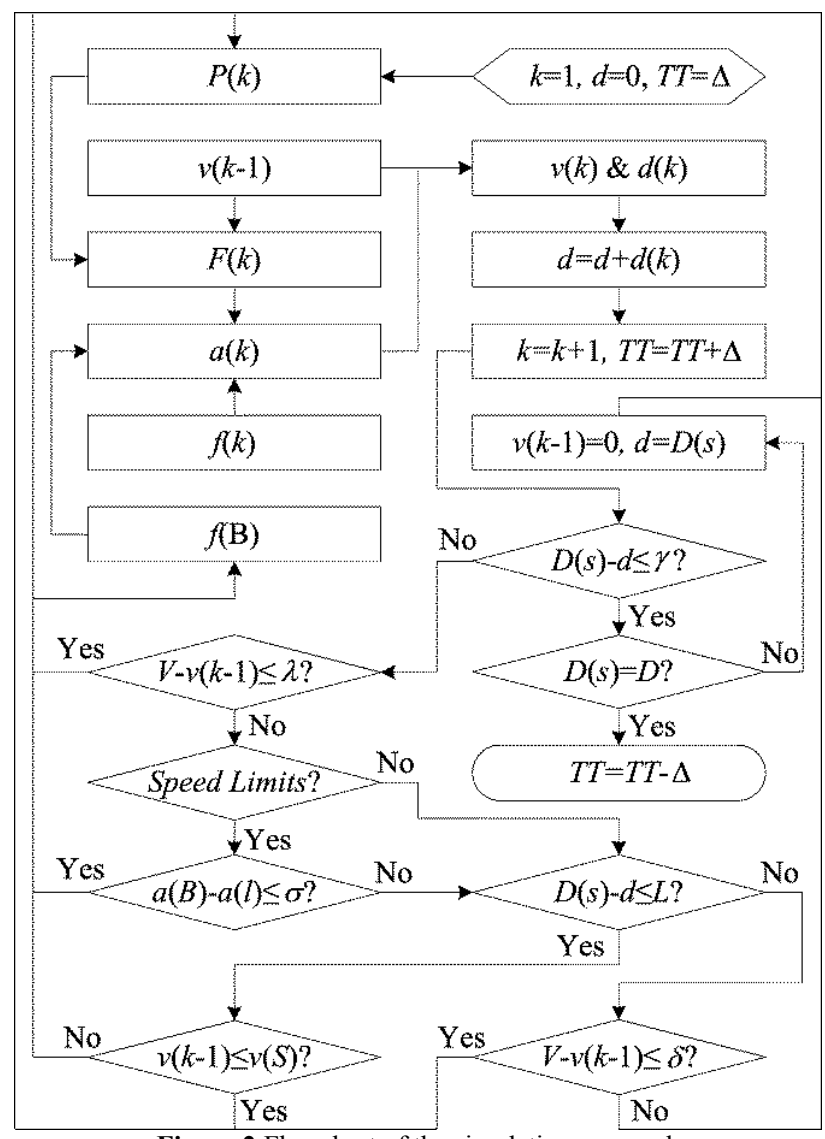

Figure 2 Flowchart of the simulation approach

The details in each step of the whole simulation process for a transport work are as follows:

Step 1: Initialize $k, d$ and $T T$;

Step 2: Obtain $F(k)$ according to $F$ for motoring of the startup or $P(k)$ and $v(k-1)$ for motoring with the full traction power, coasting or braking after the startup;

Step 3: Compute $a(k)$ based on $F(k), f(k)$ and $f(B)$ for the specific operation;

Step 4: Calculate $v(k)$ and $d(k)$ on the premise of $a(k)$ and $v(k-1)$

Step 5: Set $d=d+d(k)$;

Step 6: Set $k=k+1$ and $T T=T T+\Delta$;

Step 7: If $D(s)$ (i.e., the transport distance from the departure station of the train to the nearest station in its transport direction) and $d$ has a difference no larger than $\gamma$ which is a positive constant value, go to Step 8; else, go to Step 9;

Step 8: If $D(s)$ is equal to $D$ (i.e., the transport distance from the departure station to the terminal station), output $T T=T T-\Delta$; else, set $v(k-1)=0$ and $d=$ $D(s)$, and go to Step 2 for motoring of the startup;

Step 9: If the difference between $V$ (i.e., the target speed) and $v(k-1)$ is no larger than another positive constant value (i.e., $\lambda$ ), go to Step 2 for braking; else, continue;

Step 10: If there are some speed limit(s) to the train before its arriving at the next station, go to Step 11; else, go to Step 12;
Step 11: If $(a(\mathrm{~B})-a(l))$ is no larger than the positive constant $\sigma$, go to Step 2 for braking; else, continue;

Step 12: If $(D(s)-d)$ is no larger than the shortest braking distance of the train (i.e., $L$ ), go to Step 13; else, go to Step 14;

Step 13: If $v(k-1)$ is no larger than the safe speed (i.e., $v(S))$ at which the train is able to stop at any time, go to Step 2 for coasting; else, go to Step 2 for braking;

Step 14: If $(V-v(k-1))$ is no larger than $\delta$ which is constant and bigger than $\lambda$, go to Step 2 for coasting; else, go to Step 2 for motoring with the full traction power.

\section{Ensuring a rational PCUR for a sustainably efficient target speed}

In accordance with the TT computed on the basis of the simulation of the whole transport process of a train, the TT per $10000 \mathrm{p}-\mathrm{km}$ completed by the transport of the train is calculated by Eq. (10).

$$
\begin{aligned}
t t & =\frac{T T}{\sum_{i=1}^{n} 3600 \times 1000 \times C \times R_{i} \times D_{i}} \\
& =\frac{T T}{3600 \times 1000 \times C \times \bar{R} \times D}
\end{aligned}
$$

where,

$t t-T T$ per $10000 \mathrm{p}-\mathrm{km}$, hour(s) (h)/10 $000 \mathrm{p}-\mathrm{km}$

$C$ - Passenger capacity of a train, Passengers

$R_{i}-$ PCUR of the train for the rail section $i, \%$

$D_{i}$ - Transport distance of the train in section $i, \mathrm{~m}$

$n$ - Number of all the rail sections of the whole transport work, -

$\bar{R}-$ Average PCUR for all the sections, $\%$

$D$ - Transport distance from the departure station to the terminal station, $\mathrm{m}$.

The TT per $10000 \mathrm{p}-\mathrm{km}$ completed by the passenger transports of HSR-1 and HSR-2 taking the formation illustrated in Fig. 1 on their corresponding rail routes are shown in Fig. 3 and Fig. 4, respectively, for the changes of the target speed and the average PCUR. It is clear that the decrease of the average PCUR from $60 \%$ makes the TT per $10000 \mathrm{p}-\mathrm{km}$ increased obviously for the same target speed. On the contrary, if the average PCUR increases from $60 \%$, the TT per $10000 \mathrm{p}-\mathrm{km}$ of both the transport services provided by the studied HSR trains have no apparent changes especially when the target speeds of the trains are higher than about $80 \%$ of their corresponding designed top speeds. In addition, the decrease of the TT per $10000 \mathrm{p}-\mathrm{km}$ with the increase of the target speed of a train especially from some $80 \%$ of its designed top speed (i.e., about $280 \mathrm{~km} / \mathrm{h}$ and approximately $200 \mathrm{~km} / \mathrm{h}$ for HSR-1 and HSR-2, respectively) becomes relatively very slow if the average PCUR is over $60 \%$. Therefore, making the average PCUR of a HSR train exceed $60 \%$ is able to evidently decrease TT per $10000 \mathrm{p}-\mathrm{km}$ of its passenger transport work. Meanwhile, the target speed of a HSR train ought to reach about $80 \%$ of the designed top speed of the train to further improve its transport efficiency. Furthermore, in 
view of the dramatic increase of the traction energy cost intensity of a HSR train with its target speed [9], it is unnecessary to make the target speed of a HSR train much higher than $80 \%$ of its designed top speed from the sustainable transport perspective.

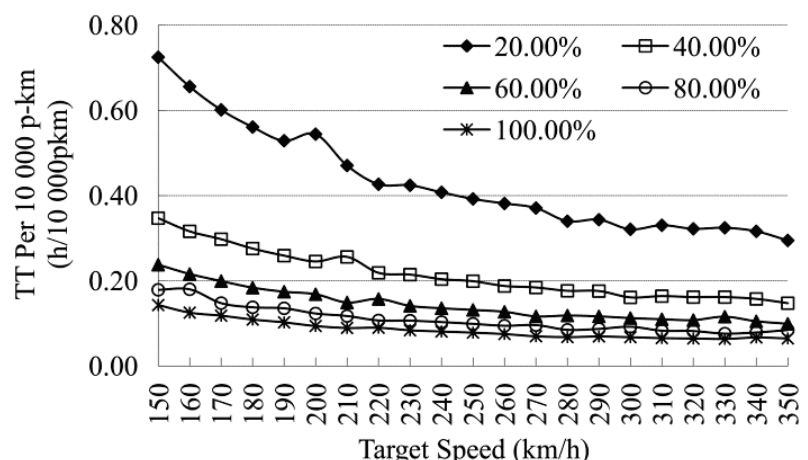

Figure 3 Changes of the TT per 10000 p-km of HSR-1 for its current formation

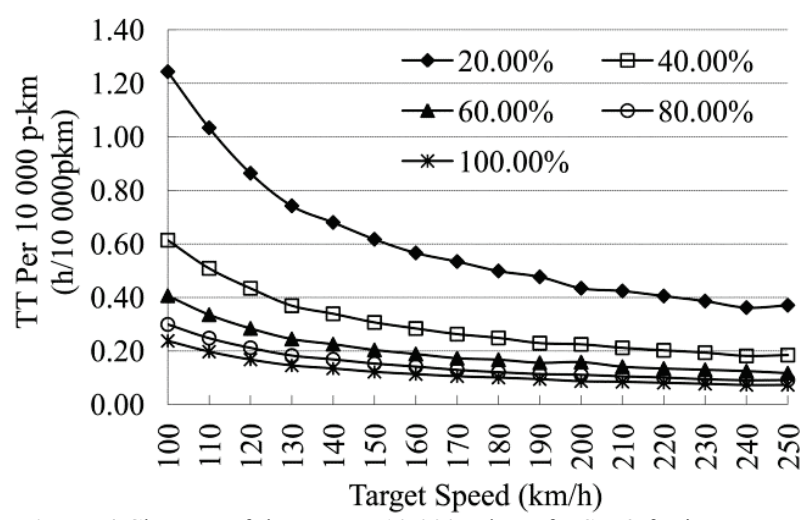

Figure 4 Changes of the TT per 10000 p-km of HSR-2 for its current formation

\section{Rationalising formation of a HSR train according to PCUR}

As illustrated in Fig. 5, either HSR-1 or HSR-2 can respectively connect the same two sets of the current formation (represented by F1) shown in Fig. 1 to get the doubled formation (denoted by F2) which doubles the full traction power of a train as well as its length and mass. In comparison to the TT per $10000 \mathrm{p}-\mathrm{km}$ of the transport services made by the studied HSR trains with F1, the TT per $10000 \mathrm{p}-\mathrm{km}$ of the same transports completed by the same trains with F2 are presented in Fig. 6 and Fig. 7 for certain average PCURs and various target speeds. The number in each pair of the brackets in both Fig. 6 and Fig. 7 indicates the PCUR of a train for its corresponding formation. If a HSR train which takes F2 and has a PCUR of no less than $60 \%$, the TT per $10000 \mathrm{p}-\mathrm{km}$ of its transport is still smaller than that of the same work completed by this train with F1 and the PCUR of even $100 \%$. As a result, it is true that, in comparison to $\mathrm{F} 1$ of a HSR train, F2 of this train helps to improve its transport efficiency if the F2 is able to get a PCUR of no less than $60 \%$.

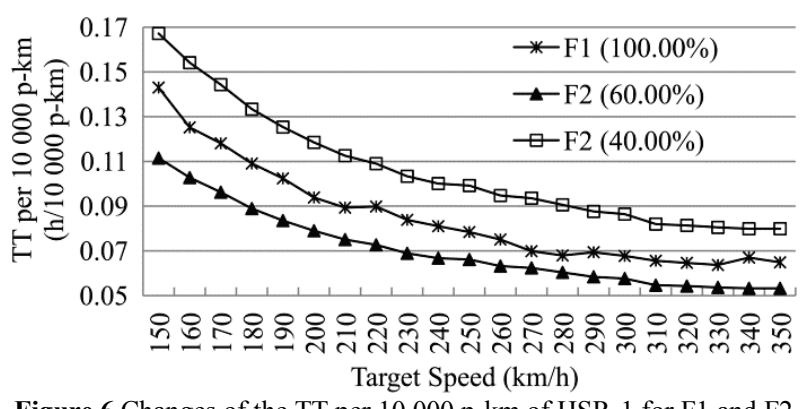

Figure 6 Changes of the TT per 10000 p-km of HSR-1 for F1 and F2

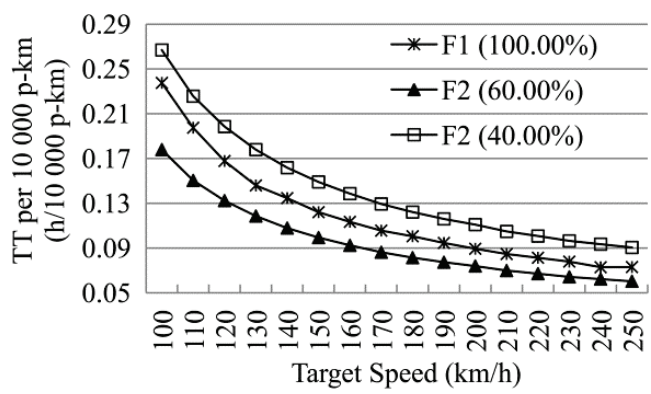

Figure 7 Changes of the TT per 10000 p-km of HSR-2 for F1 and F2

\section{Conclusions}

Now it is confirmed that if the average PCUR of a HSR train with the doubled formation explained previously becomes no less than about $60 \%$ for its entire transport process, the TT per unit of the whole transport work will be relatively very small in particular for a target speed over approximately $80 \%$ of the designed top speed of the train. Therefore, in the first place, making every effort to increase the PCUR of a HSR train over $60 \%$ ought to be encouraged to improve the transport efficiency of the train observably. In other words, $60 \%$ can be used as a benchmark to assess the PCUR of a HSR train for evaluating the efficiency of its transport work. Moreover, the target speed of a HSR train should be not only over $200 \mathrm{~km} / \mathrm{h}$ [1] but also about $80 \%$ of its designed top speed. A target speed much lower than $80 \%$ of the designed top speed of the train will distinctly decrease its transport efficiency. In contrast, at the cost of a dramatically increased energy expense, the much increase of the target speed of the train from $80 \%$ of its designed top speed will not receive a visible decrease of the TT per unit for the same transport service. At last, the doubled formation explained previously is preferred if the PCUR of a HSR train taking such a formation is over some $60 \%$.

This research still needs to be improved on several aspects. For example, only the passenger transports completed by two representative types of the HSR trains on their corresponding rail routes in China are analysed in this study. Transport services made by more types of the HSR trains on different rail routes in the world are necessary to be studied to further validate the conclusions of this work. In addition, the influence of many other factors such as very high or low temperatures upon the transport efficiency of a HSR train should be explored as well in a more integrated viewpoint. 


\section{Acknowledgements}

This research is supported by Program for New Century Excellent Talents in University (NCET-13-0655), National Natural Science Foundation of China (71571011; 71390332) and Fundamental Research Funds for the Central Universities (2016JBM028).

\section{$7 \quad$ References}

[1] The State Council of the People's Republic of China. Railway Safety Management Regulations. The Central People's Government of the People's Republic of China, Beijing, 2014.

[2] Martín, J. C.; Román, C.; García-Palomares, J. C.; Gutiérrez, J. Spatial Analysis of the Competitiveness of the High-Speed Train and Air Transport: The Role of Access to Terminals in the Madrid-Barcelona Corridor. // Transportation Research Part A: Policy and Practice. 69, (2014), pp. 392-408. DOI: 10.1016/j.tra.2014.09.010

[3] National Bureau of Statistics of China. China Statistical Yearbook 2014. China Statistics Press, Beijing, 2014.

[4] Barrena, E.; Canca, D.; Coelho, L. C.; Laporte, G. SingleLine Rail Rapid Transit Timetabling Under Dynamic Passenger Demand. // Transportation Research Part B: Methodological. 70, (2014), pp. 134-150. DOI: 10.1016/j.trb.2014.08.013

[5] Barrena, E.; Canca, D.; Coelho, L. C.; Laporte, G. Exact Formulations and Algorithm for the Train Timetabling Problem with Dynamic Demand. // Computers \& Operations Research. 44, (2014), pp. 66-74. DOI: 10.1016/j.cor.2013.11.003

[6] Niu, H.; Zhou, X.; Gao, R. Train Scheduling for Minimizing Passenger Waiting Time with Time-Dependent Demand and Skip-Stop Patterns: Nonlinear Integer Programming Models with Linear Constraints. // Transportation Research Part B: Methodological. 76, (2015), pp. 117-135. DOI: 10.1016/j.trb.2015.03.004

[7] Isaai, M. T.; Kanani, A.; Tootoonchi, M.; Afzali, H. R. Intelligent Timetable Evaluation Using Fuzzy AHP. // Expert Systems with Applications. 38, 4(2011), pp. 37183723. DOI: 10.1016/j.eswa.2010.09.030

[8] Lindgreen, E.; Sorenson, S. C. Simulation of Energy Consumption and Emissions from Rail Traffic Evaluation (Report No: MEK-ET-2005-04). Technical University of Denmark, Lyngby, 2005.

[9] Feng, X. Optimization of Target Speeds of High-Speed Railway Trains for Traction Energy Saving and Transport Efficiency Improvement. // Energy Policy. 39, 12(2011), pp. 7658-7665. DOI: 10.1016/j.enpol.2011.08.051

[10] Freyss, M.; Giesen, R.; Mu-oz, J. C. Continuous Approximation for Skip-Stop Operation in Rail Transit. // Transportation Research Part C: Emerging Technologies, 36. (2013), pp. 419-433. DOI: 10.1016/j.trc.2013.07.004

[11] Givoni, M.; Banister, D. Speed: The Less Important Element of the High-Speed Train. // Journal of Transport Geography. 22, (2012), pp. 306-307. DOI: 10.1016/j.jtrangeo.2012.01.024

[12] Zhou, X.; Zhong, M. Bicriteria Train Scheduling for HighSpeed Passenger Railroad Planning Applications. // European Journal of Operational Research. 167, 3(2005), pp. 752-771. DOI: 10.1016/j.ejor.2004.07.019

[13] Feng, X.; Wang, X.; Zhang, H. Passenger Transfer Efficiency Optimization Modelling Research with Simulations. // International Journal of Simulation Modelling. 13, 2(2014), pp. 210-218. DOI: 10.2507/IJSIMM13(2)CO7
[14] Fu, H.; Nie, L.; Meng, L.; Sperry, B. R.; He, Z. A Hierarchical Line Planning Approach for a Large-Scale High Speed Rail Network: The China Case. // Transportation Research Part A: Policy and Practice. 75, (2015), pp. 61-83. DOI: 10.1016/j.tra.2015.03.013

[15] Espinosa-Aranda, J. L.; García-Ródenas, R.; RamírezFlores, M. C.; López-García, M. L.; Angulo, E. High-Speed Railway Scheduling Based on User Preferences. // European Journal of Operational Research. 246, 3(2015), pp. 772-786. DOI: 10.1016/j.ejor.2015.05.052

[16] International Union of Railways. UIC Code 556 OR: Loadings of Coach Bodies and Their Components. 3rd ed. International Union of Railways, Paris, 1990.

\section{Authors' addresses}

\section{Xuesong Feng, Associate Professor, PhD}

MOE Key Laboratory for Urban Transportation Complex Systems Theory and Technology, Beijing Jiaotong University,

No. 3 Shangyuancun, Haidian District, Beijing 100044, P. R. China E-mail: xsfeng@bjtu.edu.cn

\section{Yuanpeng Jie, Master student}

School of Traffic and Transportation, Beijing Jiaotong University, No. 3 Shangyuancun, Haidian District, Beijing 100044, P. R. China E-mail:15120825@bjtu.edu.cn

Haidong Liu, Associate Professor, PhD

Integrated Transport Research Center of China, Beijing Jiaotong University,

No. 3 Shangyuancun, Haidian District, Beijing 100044, P. R. China E-mail: hdliu@bjtu.edu.cn

Bin Xu, Lecturer, Master

MOE Key Laboratory for Urban Transportation Complex Systems Theory and Technology, Beijing Jiaotong University, No. 3 Shangyuancun, Haidian District, Beijing 100044, P. R. China E-mail: bxu@bjtu.edu.cn 